\title{
Consideration of the ethnic prevalence of genotypes in the clinical use of tacrolimus
}

\author{
"Polymorphisms in the CYP3A5 gene explain $40-50 \%$ of the variability \\ in tacrolimus dose requirement, at least in Caucasians. The residual \\ variability in tacrolimus clearance is at yet unexplained."
}

First draft submitted: 5 August 2016; Accepted for publication: 8 August 2016; Published online: 28 October 2016

Keywords: CYP3A5 • ethnicity • tacrolimus • transplantation

\begin{abstract}
Tacrolimus is the mainstay of immunosuppressive therapy after solid organ transplantation for the prevention of acute rejection. Even though the use of tacrolimus-based immunosuppressive therapy has resulted in improved patient and graft survival, there unfortunately are some drawbacks. The associated adverse events, including nephrotoxicity, post-transplantation diabetes mellitus and hypertension remain an important issue [1]. To complicate matters further, the therapeutic range between efficacy and toxicity is narrow and tacrolimus is known to have a high interindividual pharmacokinetic variability [2]. Underexposure to tacrolimus could lead to an increased risk of rejection, whereas overexposure has been associated with an increased risk of toxicity. To individualize tacrolimus therapy, therapeutic drug monitoring (TDM) is routinely performed.
\end{abstract}

\section{Pharmacogenetic aspects of tacrolimus exposure}

The interindividual variability in tacrolimus pharmacokinetics is partly explained by genetic polymorphisms in genes encoding for tacrolimus metabolizing enzymes. CYP3A5 and to a lesser extent CYP3A4 are considered the fundamental enzymes involved in the metabolism of tacrolimus [3]. Individuals carrying at least one $C Y P 3 A 5^{*} 1$ allele are referred to as CYP3A5 expressers, whereas individuals homozygous for the $C Y P 3 A 5^{*} 3$ allele are known as CYP3A5 nonexpressers.
The $C Y P 3 A 5^{*} 3$ allele causes alternative splicing which results in protein truncation and a severe decrease of functional CYP3A5 enzyme [4]. It has been consistently demonstrated that CYP3A5 expressers require at least a 1.5-fold higher tacrolimus dose compared with CYP3A5 nonexpressers to reach the same exposure [5]. Following standard, bodyweight-based dosing, CYP3A5 expressers also appear to have a delay in achieving target tacrolimus exposure, in spite of TDM [6]. In one study, CYP3A5 expressers developed acute rejection earlier compared with nonexpressers [6].

Two randomized-controlled trials (RCTs) in which kidney transplant recipients either received the standard, bodyweight-based tacrolimus dosage or a CYP3A5 genotypebased tacrolimus dosage (with expressers getting a higher than standard dose and nonexpressers receiving a lower dose) have been conducted. In the first trial, significantly more genotype-dosed patients reached the target range at first steady state compared with bodyweight-based tacrolimus dosing [7]. The second trial, however, found no such advantage of CYP3A5-guided tacrolimus dosing [8]. However, neither study demonstrated a decreased risk of acute rejection nor any other clinical benefit, and the conclusions were that optimization of the initial tacrolimus dose using CYP3A5 pharmacogenetic testing does not improve clinical outcomes when TDM is
Louise M Andrews

Author for correspondence: Department of Hospital Pharmacy, Erasmus Medical Center, Room Na-206, P.O. Box 2040, 3000 CA, Rotterdam, The Netherlands

Tel.: +31 107033202

Fax: +31 107032400

L.Andrews@erasmusmc.nl

Brenda CM De Winter Department of Hospital Pharmacy, Erasmus Medical Center, Room Na-206, P.O. Box 2040, 3000 CA, Rotterdam, The Netherlands

\section{Teun Van Gelder}

Department of Hospital Pharmacy, Erasmus Medical Center, Room Na-206, P.O. Box 2040, 3000 CA, Rotterdam, The Netherlands and

Department of Internal Medicine, Nephrology \& Transplantation, Erasmus Medical Center, Rotterdam, The Netherlands

Dennis A Hesselink Department of Internal Medicine, Nephrology \& Transplantation, Erasmus Medical Center, Rotterdam, The Netherlands 
performed $[7,8]$. It seems that TDM is able to rapidly correct for any tacrolimus exposure outside the target range [9]. Consequently, the time patients may be underexposed typically lasts only a few days, which may not be long enough to cause a clinically relevant increase in the incidence of acute rejection. These findings do not support routinely genotyping kidney transplant recipients for CYP3A5.

\section{"Other interethnic differences, including comedication and diet, could turn out to be the missing pieces of the puzzle."}

CYP3A4 genotype has also been associated with altered tacrolimus clearance [10]. The recently discovered $C Y P 3 A 4^{*} 22$ SNP has been associated with lower tacrolimus dose requirements after renal transplantation. After combining both CYP3A4 and CYP3A5 genotypes, Elens et al. were able to better predict the tacrolimus-metabolizing phenotype of kidney transplant patients [11]. Fairly recently the CYP3A4*26 SNP was described, which results in exceptionally low tacrolimus dose requirement [12].

\section{Ethnic considerations}

In USA in 2015, 55.5\% of the transplant recipients were Caucasian, 21.8\% African-American (AA) and 15.5\% of Hispanic descent [13]. AA kidney recipients are considered a high-risk group, having an increased risk of acute rejection and graft loss compared with non-AA recipients. The reasons for this increased risk are multiple and include differences in immunoreactivity, socioeconomic status, HLA matching, longer time on dialysis and lower rates of living kidney donation. In addition, compared with non-AA transplant recipients, differences exist in the adherence to the immunosuppressive medication and the pharmacokinetics of tacrolimus [14]. AA recipients in general have a higher tacrolimus clearance than Caucasians, and therefore require higher doses to reach the target range [15]. The reasons for these differences are poorly understood.

Part of the differences in tacrolimus pharmacokinetics and transplantation outcomes may relate to differences between populations in the genetics of tacrolimus-metabolizing enzymes. The best-known example is the allelic frequency of the loss-of-function CYP $3 A 5^{*} 3$ allele. This SNP is common among Caucasians (90-93\%), but is less prevalent among Asians $(60-73 \%)$ and even more so in AA (32\%) [16]. It has been suggested that all AA recipients should therefore receive a higher tacrolimus starting dose $(0.3 \mathrm{mg} / \mathrm{kg}$ per day) [17].

For a long time the low prevalence of the $C Y P 3 A 5^{*} 3$ allele in AA was considered the cause of the rapid metabolizer phenotype in this population. However, recent investigations have demonstrated that the two loss-of-function SNPs $C Y P 3 A 5^{*} 6$ and $C Y P 3 A 5^{*} 7$ are quite prevalent among AA individuals with $75 \%$ carrying one or more nonfunctional CYP $3 A 5$ alleles (either ${ }^{*} 3,{ }^{*} 6$ or ${ }^{*} 7$ ), and as much as $24 \%$ homozygous for all three alleles. This finding implicates that there are substantially more CYP3A5 nonexpressing AA than previously assumed. The presence of the ${ }^{*} 6$ and ${ }^{*} 7$ SNPs among AA may 'compensate' for the lower prevalence of $C Y P 3 A 5^{*} 3$ allele, resulting in a metabolic phenotype similar to that of Caucasians $[15,18]$. This finding supports the hypothesis that the differences in tacrolimus pharmacokinetics between AA and non-AA recipients might not be genetic.

\section{Residual variability \& future perspective}

Polymorphisms in the CYP3A5 gene explain $40-50 \%$ of the variability in tacrolimus dose requirement, at least in Caucasians $[7,8]$. The residual variability in tacrolimus clearance is at yet unexplained. It is likely that other, as yet to be identified genetic variants in enzymes or drug transporter proteins will be discovered in the future but we feel that it is unlikely that the differences between patients of different ethnicity will be completely explained by genetics. Other interethnic differences, including comedication and diet, could turn out to be the missing pieces of the puzzle. When studied under matched conditions, there were no differences in pharmacokinetics and pharmacodynamics of ciclosporin (also a calcineurin inhibitor and CYP3A substrate) [19]. This implicates that differences in dietary habits might explain, at least to some extent, the pharmacokinetic differences between Caucasian and AA transplant recipients.

Most of our knowledge on the pharmacogenetics of tacrolimus comes from studies which mostly included non-AA patients. Therefore, this knowledge cannot be directly extrapolated to non-Caucasian patients which make up a relatively large proportion of kidney transplant recipients in USA and UK. Because AA tend to do less-well after transplantation, it is important to improve immunosuppressive drug pharmacotherapy for this group.

Fairly recently, dosing algorithms have been proposed to better individualize the starting dose of tacrolimus [20]. The dosing algorithm developed by Passey et al. incorporated a combination of genetic (CYP3A5 genotype), demographic (age) and clinical (days post-transplant, steroid use and calcium channel blocker use) information [21]. The algorithm was developed in a population that for $20 \%$ consisted of AA. It was successfully validated, however it was not able to accurately predict tacrolimus clearance in a prospective 
study [22]. The use of dosing algorithms that incorporate more factors than just bodyweight and $C Y P 3 A 5$ genotype seems a more precise and rational approach. New dosing algorithms need to be developed specifically for AA recipients and should be validated and tested in an independent cohort of AA patients [18]. To justify clinical incorporation of such a populationspecific algorithm, a clinical trial should demonstrate the superiority of such an approach over conventional dosing followed by TDM.

An alternative and possibly more simple strategy could be to only adjust the initial tacrolimus dose in a selected group of patients. Post hoc analyses of the above-mentioned RCT demonstrated that CYP3A5 expressers tended to be below the target range less frequently if they received a higher tacrolimus starting dose [8]. AA recipients are more often rapid metabolizers than Caucasians and prescribing these patients a higher starting dose makes sense. It would be interesting to study the utility of comprehensive pharmacogenetic testing in this population. $C Y P 3 A 5^{*} 1$ and $C Y P 3 A 5^{*} 3$ have been the main focus so far, but we now know that this is insufficient in AA transplant recipients. $C Y P 3 A 5^{*} 6$ and $C Y P 3 A 5^{*} 7$ need to be taken into consideration [15]. Given the proactive nature of pharmacogenetic testing, it has the potential to optimize immunosuppressive therapy but it will most likely remain a complimentary tool to traditional pharmacokinetic TDM.

A final strategy could be to prescribe a different tacrolimus formulation to AA recipients that has a more favorable pharmacokinetic profile. LCPT (Envarsus ${ }^{\circledR}$; Veloxis Pharmaceuticals, Hørsholm, Denmark) is an extended-release formulation of tacrolimus designed for once-daily administration. The difference between LCPT and other forms of once- and twicedaily tacrolimus products is the proprietary MeltDose ${ }^{\circledR}$ drug delivery technology (Veloxis Pharmaceuticals). MeltDose is designed to improve the bioavailability of drugs with low water solubility (i.e. Biopharmaceutics Classification System Class II compounds). The release of tacrolimus from LCPT tablets and absorption occurs more distally in the small bowel or colon as compared with the conventional twice-daily

\section{References}

1 De Jonge H, Naesens M, Kuypers DR. New insights into the pharmacokinetics and pharmacodynamics of the calcineurin inhibitors and mycophenolic acid: possible consequences for therapeutic drug monitoring in solid organ transplantation. Ther. Drug Monit. 31(4), 416-435 (2009).

2 Antignac M, Barrou B, Farinotti R, Lechat P, Urien S. Population pharmacokinetics and bioavailability of formulation [23]. Gut CYP3A activity is largest in the proximal small bowel and progressively decreases downstream in the GI tract [24]. Due to the delayed release effect of LCPT, tacrolimus is mostly released in the distal GI tract, and its absorption is less dependent on CYP3A (and CYP3A genotype) which leads to an increased bioavailability, and therefore a decreased dose requirement. It also causes a lower tacrolimus peak concentration, which has been associated with less toxicity $[25,26]$. The recommended dose of LCPT as described in the package insert is $70 \%$ of the standard dose in Caucasian patients and $85 \%$ in AA [27]. This suggests that LCPT may improve the pharmacokinetic profile of tacrolimus, particularly in CYP3A5 expressers. Whether LCPT is a more suitable formulation for rapid tacrolimus metabolizers is currently under investigation [28].

Over the past decade we have learned a great deal about the pharmacokinetics and pharmacogenetics of tacrolimus. This is also the case for ethnic minorities. However, many questions remain unanswered and there is room to improve tacrolimus pharmacotherapy in ethnic minorities. We believe that optimized tacrolimus dosing by use of (ethnicity-specific) dosing algorithms and possibly, the use of delayed-release tacrolimus formulations are rational strategies to achieve this goal. Finally and perhaps most importantly, RCTs should be designed and conducted specifically for patients of non-Caucasian ethnicity.

\section{Financial \& competing interests disclosure}

$T$ van Gelder has received lecture fees from Chiesi Pharmaceuticals and Astellas Pharma B.V., and consulting fees from Astellas Pharma B.V., Novartis Pharma B.V., Roche Pharma, Teva Pharma and Sandoz Pharma. DA Hesselink has received lecture and consulting fees, as well as grant support from Astellas Pharma B.V., Bristol-Myers Squibb, Chiesi Pharmaceuticals, MSD Pharmaceuticals, Novartis Pharma B.V., and Roche Pharma. The authors have no other relevant affiliations or financial involvement with any organization or entity with a financial interest in or financial conflict with the subject matter or materials discussed in the manuscript apart from those disclosed.

No writing assistance was utilized in the production of this manuscript.

tacrolimus in kidney transplant patients. Brit. J. Clin. Pharmacol. 64(6), 750-757 (2007).

3 Dai $\mathrm{Y}$, Hebert MF, Isoherranen $\mathrm{N}$ et al. Effect of CYP3A5 polymorphism on tacrolimus metabolic clearance in vitro. Drug Metab. Dispos. 34(5), 836-847 (2006).

4 Kuehl P, Zhang J, Lin Y et al. Sequence diversity in CYP3A promoters and characterization of the genetic basis of polymorphic CYP3A5 expression. Nat. Genet. 27(4), 383-391 (2001). 
5 Picard N, Bergan S, Marquet P et al. Pharmacogenetic biomarkers predictive of the pharmacokinetics and pharmacodynamics of immunosuppressive drugs. Ther. Drug Monit. 38(Suppl. 1), S57-S69 (2016).

6 Macphee IA, Fredericks S, Tai T et al. The influence of pharmacogenetics on the time to achieve target tacrolimus concentrations after kidney transplantation. Amer. J. Transplant. 4(6), 914-919 (2004).

7 Thervet E, Loriot MA, Barbier S et al. Optimization of initial tacrolimus dose using pharmacogenetic testing. Clin. Pharmacol. Ther. 87(6), 721-726 (2010).

8 Shuker N, Bouamar R, Van Schaik RH et al. A randomized controlled trial comparing the efficacy of CYP3A5 genotypebased with bodyweight-based tacrolimus dosing after living donor kidney transplantation. Amer. J. Transplant. 16(7), 2085-2096 (2016).

9 Van Gelder T, Hesselink DA. Dosing tacrolimus based on CYP3A5 genotype: will it improve clinical outcome? Clin. Pharmacol. Ther. 87(6), 640-641 (2010).

10 De Jonge H, De Loor H, Verbeke K, Vanrenterghem Y, Kuypers DR. In vivo CYP3A4 activity, CYP3A5 genotype, and hematocrit predict tacrolimus dose requirements and clearance in renal transplant patients. Clin. Pharmacol. Ther 92(3), 366-375 (2012).

11 Elens L, Van Schaik RH, Panin N et al. Effect of a new functional CYP3A4 polymorphism on calcineurin inhibitors' dose requirements and trough blood levels in stable renal transplant patients. Pharmacogenomics 12(10), 1383-1396 (2011).

12 Werk AN, Lefeldt S, Bruckmueller $\mathrm{H}$ et al. Identification and characterization of a defective CYP3A4 genotype in a kidney transplant patient with severely diminished tacrolimus clearance. Clin. Pharmacol. Ther. 95(4), 416-422 (2014).

13 Organ Procurement and Transplantation Network. https://optn.transplant.hrsa.gov/

14 Narayanan M, Pankewycz O, Shihab F, Wiland A, Mccague K, Chan L. Long-term outcomes in African American kidney transplant recipients under contemporary immunosuppression: a four-yr analysis of the Mycophenolic acid Observational REnal transplant (MORE) study. Clin. Transplant. 28(2), 184-191 (2014).

15 Oetting WS, Schladt DP, Guan W et al. Genomewide association study of tacrolimus concentrations in African American kidney transplant recipients identifies multiple CYP3A5 alleles. Amer. J. Transplant. 16(2), 574-582 (2016).

16 Tang JT, Andrews LM, Van Gelder T et al. Pharmacogenetic aspects of the use of tacrolimus in renal transplantation: recent developments and ethnic considerations. Expert Opin. Drug Metab. Toxicol. 12(5), 555-565 (2016).

17 Vadivel N, Garg A, Holt DW, Chang RW, Macphee IA. Tacrolimus dose in black renal transplant recipients. Transplantation 83(7), 997-999 (2007).
18 Sanghavi K, Brundage RC, Miller MB et al. Genotypeguided tacrolimus dosing in African-American kidney transplant recipients. Pharmacogenomics J. doi:10.1038/ tpj.2015.87 (2015) (Epub ahead of print).

19 Stein CM, Sadeque AJ, Murray JJ, Wandel C, Kim RB, Wood AJ. Cyclosporine pharmacokinetics and pharmacodynamics in African American and white subjects. Clin. Pharmacol. Ther. 69(5), 317-323 (2001).

20 Andrews LM, Riva N, De Winter BC et al. Dosing algorithms for initiation of immunosuppressive drugs in solid organ transplant recipients. Expert Opin. Drug Metab. Toxicol. 11(6), 921-936 (2015).

21 Passey C, Birnbaum AK, Brundage RC, Oetting WS, Israni AK, Jacobson PA. Dosing equation for tacrolimus using genetic variants and clinical factors. Brit. J. Clin. Pharmacol. 72(6), 948-957 (2011).

22 Boughton O, Borgulya G, Cecconi M, Fredericks S, Moreton-Clack M, Macphee IA. A published pharmacogenetic algorithm was poorly predictive of tacrolimus clearance in an independent cohort of renal transplant recipients. Brit. J. Clin. Pharmacol. 76(3), 425-431 (2013).

23 Nigro V, Glicklich A, Weinberg J. Improved Bioavailability of MELTDOSE once-daily formulation of tacrolimus (LCPTacro) with controlled agglomeration allows for consistent absorption over $24 \mathrm{hrs}$ : a scintigraphic and pharmacokinetic evaluation. Amer. J. Transplant. 13(Suppl. 5), 339 (2013).

24 Thörn M, Finnström N, Lundgren S, Rane A, Lööf L. Cytochromes P450 and MDR1 mRNA expression along the human gastrointestinal tract. Brit. J. Clin. Pharmacol. 60(1), 54-60 (2005).

25 Budde K, Bunnapradist S, Grinyo JM et al. Novel oncedaily extended-release tacrolimus (LCPT) versus twice-daily tacrolimus in de novo kidney transplants: one-year results of Phase III, double-blind, randomized trial. Amer. J. Transplant. 14(12), 2796-2806 (2014).

26 Langone A, Steinberg SM, Gedaly R et al. Switching study of kidney transplant patients with tremor to LCP-Tacro (STRATO): an open-label, multicenter, prospective Phase $3 \mathrm{~b}$ study. Clin. Transplant. 29(9), 796-805 (2015).

27 European Medicines Agency. www.ema.europa.eu/

28 Trofe-Clark J, Brennan D, West-Thielke P, Milone M, Lim M, Bloom R. A randomized cross-over Phase $3 \mathrm{~b}$ study of the pharmacokinetics of once-daily extended release MeltDose ${ }^{\circledR}$ tacrolimus (Envarsus ${ }^{\circledast} \mathrm{XR}$ ) versus twice-daily tacrolimus in African-Americans (ASERTAA). Amer. J. Transplant. 15(Suppl. 3), Abstract (2015). www.atcmeetingabstracts.com/ 